\title{
How to Improve Students' Comprehension concerning the Major Terms of Functional Groups?--In the Experiment of OrCheTaboo Game
}

\author{
Nalan Akkuzu ${ }^{1} \&$ Melis Arzu Uyulgan ${ }^{1}$ \\ ${ }^{1}$ Dokuz Eylül University, Buca Education Faculty, Department of Secondary Science and Mathematics Education, \\ Izmir, Turkey \\ Correspondence: Nalan Akkuzu, Dokuz Eylül University Buca Education Faculty Department of Secondary Science \\ and Mathematics Education, Izmir, Turkey. Tel: 90-232-301-2409. E-mail: nalan.akkuzu@gmail.com
}

Received: March 11, 2016

Accepted: March 24, 2016

Online Published: March 31, 2016

doi:10.5430/ijhe.v5n2p196

URL: http://dx.doi.org/10.5430/ijhe.v5n2p196

\begin{abstract}
In this research, for an effective learning of concepts in the scope of functional groups in organic chemistry, it has been developed as "Organic Chemistry Taboo (OrCheTaboo)" which is an educational activity by the researchers. The aim of this study is to analyze the effect of the game OrCheTaboo on learning of concepts related to functional groups. The study group of the research consists of 62 students who took the Organic Chemistry Laboratory Course in the spring term and they enrolled in the Department of Secondary Science and Mathematics Education of a Faculty of Education at a state university in Turkey. Quasi-experimental design with pretest-posttest control group has been used. As a result, the game OrCheTaboo gives the opportunity to be in conceptual development processes like describing the terms to the students, identifying from the other terms or establishing its similar characteristics with the other terms, put their relation forward. Because of these characteristics, while turning the complicated and difficult terms, the game has a positive and active role.
\end{abstract}

Keywords: Functional group, Organic chemistry, Taboo game, Concept learning

\section{Introduction}

In chemistry teaching, teaching through game is one of the most frequently used methods in education practices that provide the lessons to be more productive, entertaining, dynamic and the active participation of students (Campbell \& Muzyka, 2002; Capps, 2008; Deavor, 2001; Greengold, 2005; Hanson, 2002; Knudtson, 2015; Koether, 2003; Michalek \& Hanson, 2006; Stringfield \& Kramer, 2014). The studies that have been carried out have revealed that this method has many contributions like increasing the interest in the class, focusing the attention, affecting the student motivation positively, increasing the personal self-confidence, improving the social-cognitive skills (Crute, 2010; Gmitrova, Podhajecká, \& Gmitrov, 2009; Kavak, 2012; Rieber, Smith, \& Noah, 1998; Samide \& Wilson, 2014). Teaching through game is an effective education method which can be applied in many stages of education from primary school to university (Russell, 1999; Samide \& Wilson, 2014; Williams, 2008). In teaching the concepts, educational games are also shown as education tools that contribute to strengthen the materializing and identification of the concepts (Crute, 2010; Knudtson, 2015). With the aim of reinforcing the concepts in the scope of any topic, it is possible to create educational activities that are suitable to be applied individually, in teams or at all grades through different game designs (Garris, Ahlers, \& Driskell, 2010; Samide \& Wilson, 2014).

The language of chemistry is a whole that consists of symbols, formulas, chemical equations and many terms with specific meanings (Kind, 2004; Sarma, 2006). To understand chemistry, it is necessary to learn the terminology of it and to associate it with chemical principles and concepts (DeVos, Van Berkel, \& Verdonk, 1994; Jensen, 1998; Suits, 2000). When the chemical terminology and the organization of it structured well for the students, it is easier for them to learn the new information (Sarma, 2006). That the concept of chemistry is abstract, that it is hard to comprehend it at a microscopic and symbolic level, cause the students to be tend towards memorization and avoids the realization of the right, consistent learning (Gabel, Samuel, \& Hunn, 1987; Russell et al., 1997). The main problem in chemistry education is to improve the conceptual comprehension of students and to make it easier to learn concepts (Sanger, Phelps, \& Fienhold, 2000). Educational activities like teaching through game in chemistry classes provide positive motivation and self-confidence of success and eases to learn concepts by changing the apprehensive perspective of the students against chemistry classes (Bayir, 2014; Costa, 2007; Franco-Mariscal, Oliva-Martinez, \& Bernal-Marquez, 2012; Kavak, 2012). Besides, not only by taking notes like in classic education, but also by 
participating actively to the class, it increases their mastery of the subject (Samide \& Wilson, 2014). There are educational samples that have been applied in teaching chemistry. Some of them have been applied in following topics; Lewis structures and VSEPR theory (Myers, 2003); molecular geometry (Knudtson, 2015); nomenclature and properties of chemical species (Crute, 2000); organic chemistry (Angelin \& Ramström, 2010; Schreck, 1992); reaction rate theory (Olbris \& Herzfeld, 2002); laboratory safety (Gublo, 2003), chemical formulas, covalent and ionic compounds (Morris, 2011) and periodic table (Bayir, 2014; Kavak, 2012).

The organic chemistry is a quite wide-ranging chemical field including molecular structure, aromatic compounds, substitution, elimination, addition reaction mechanisms, isomerism, functional groups, and spectroscopy. In organic chemistry, one of the topics that students have difficulty in comprehending is the functional groups (Hassan, Hill, \& Reid, 2004; Knudtson, 2015). As it is a quite wide-ranging topic, it is complicated and hard to comprehend for the students who study with the concept and term repository of organic chemistry. Ellis (1994) associated difficulties with organic chemistry with three issues: (1) it has no problem-solving algorithms; (2) it requires three-dimensional thinking; and (3) it has an extensive new vocabulary. To comprehend the reaction mechanisms and the formation of molecular structures in organic chemistry, the students have to relate the concepts in functional groups and their movements in reactions (Hassan, Hill, \& Reid, 2004). Thus, the necessity of structuring a conceptual framework which is far from memorization and clearer about the topic of functional groups and concretizing the terminology in the content of the topic comes out. In this scope, it is possible to strengthen the conceptual comprehension of the topic by adding activities of teaching through game.

In the body of literature, there are activities of teaching through game like card games, group games and web-based games. Angelin and Ramström (2010) have prepared 24 cards about organic compounds in their card game called "where's ester". As a result of their study, they have stated that these games are helpful for students to learn organic structures and their names without memorizing them. In his research he carried out with university students about organic reactions, Erdik (2005) has developed a card activity based on finding the intermediate and end products in ketone reactions. Eastwood (2013) has applied an educational teamwork activity on the topics of nomenclature, isomerism, and basic reactions schemes in his research. He has stated that teaching through game is a meaningful method for students to learn the concepts of organic chemistry. Knudtson (2015) has carried out an activity that is based on asking and answering on the topic of organic functional groups in his card game called ChemKarta. He has stated that these kinds of activities are entertaining and effective to be applied in the classroom environment (Knudtson, 2015). In another research, there is a sample of teaching through a web based game about spectroscopy (Bradley, Lancashire, Lang, \& Williams, 2009).

In addition to these examples, the Taboo game is another active learning activity which dynamises the class and provides a practical learning and entertaining education. During the recent years, the Taboo game has been adapted to other scientific fields like maths (Türk, Güngör, \& Karaaslan, 2011), biology (Olimpo, Davis, Lagman, Parekh, \& Shields, 2010) besides chemistry (Capps, 2008), as an educational activity and applied effectively. The Taboo game is an educational game that is based on description, provides the opportunity to improve vocabulary (Genç, Genç, \& Yüzüak, 2012; Güney \& Aytan, 2014). With this characteristic, it is possible to be used as an effective and entertaining way of teaching concepts and terminology of chemistry. Moreover, it strengthens the teamwork as it is a game played by creating teams and with the aim of winning over (Capps, 2008). The Taboo game has been successfully applied in his research while learning general concepts of chemistry. Based on this, for an effective learning of concepts in the scope of functional groups in organic chemistry, "OrCheTaboo" which is an educational activity has been developed by the researchers in this study. It is regarded to be significant as this game is helpful for university students in learning the concepts of functional groups and as it contributes to the literature on organic chemistry education.

\subsection{The purpose of the study}

The aim of this study is to analyze the effect of the game OrCheTaboo on learning of concepts about functional groups in organic chemistry.

The problem that is discussed with this aim in the research is;

Does the game OrCheTaboo has an effect on students' learning of the concepts related to functional groups?

\subsubsection{The sub problems of the research}

From the aspect of learning the concepts related to functional groups of the students who participate in the experimental and control group;

1. In the grand total of their scores, is there a significant difference between their pretests? 
2. In the grand total of their scores, is there a significant difference between their posttests?

3. For each test, is there a significant difference between their posttests?

4. What are the opinions of the experimental group about the game OrCheTaboo?

\section{Methodology}

In this research, quasi-experimental design with pretest- posttest control group, which has been equalized with the aim of analyzing the effect of the game OrCheTaboo on the learning of the concepts related to functional groups in Organic Chemistry, has been used (Christensen, 2004; Cohen, Manion, \& Morrison, 2005; Marczyk, DeMatteo, \& Festinger, 2005). The quasi-experimental design which is one of the most frequently preferred designs in educational surveys is used in any case that it is not possible to keep all the variables in the research under control. With this design, the groups are created as experimental and control groups through random assignment (Büyüköztürk, 2007; Johnson \& Christensen, 2000; Karasar, 2005).

Table 1. The symbolic demonstration of the research design

\begin{tabular}{llll}
\hline Group & Pretest & Process & Posttest \\
\hline Experimental & $\mathrm{X} 1$ & $\begin{array}{l}\text { The laboratory experiments of organic chemistry } \\
\text { and activity of OrCheTaboo game }\end{array}$ & X1-X2 \\
Control & $\mathrm{X} 1$ & The laboratory experiments of organic chemistry & $\mathrm{X} 1$ \\
\hline
\end{tabular}

X1: Functional group term tests (FGTTs); X2: Open-ended interview questions

The symbolic demonstration of the research is as in Table 1. During the research, "Functional groups term tests" have been applied on experimental and control groups as pretest and at the end of the twelve week experiment and application process, as posttest.

\subsection{The study group}

The study group of the research consisted of 62 students who enrolled in the Department of Secondary Science and Mathematics Education of Faculty of Education at a state university in Turkey in spring semester and they received Organic Chemistry Laboratory class throughout the semester. While the ages of the students varied between 19 and 22,36 of them were female and 26 of them were male. In our study, students were selected via probability random sampling assignment method in groups and were separated into two groups as control group ( $\mathrm{N}=30)$ and experimental group ( $\mathrm{N}=32$ ). During the research, at the beginning of the study, we have asked open-ended questions at a basic level to the students to avoid the non-objective grouping, which treats the internal validity, and thus to find out if the students are equal to each other or not and finally, there have not been any significant difference found out between the mean of the results of the two groups. Besides, we performed a preliminary lesson with all students before the study for the purpose of equalizing their prior knowledge and removing lack of knowledge and misconceptions regarding the basic chemistry subjects and concepts related with functional groups. Moreover, if there is not any significant difference between the pretest scores, it is possible to mention the equality of groups relatively. Also, the students received the Organic Chemistry lesson from the same teacher. All students already had the basic knowledge about these topics as they received organic chemistry lesson during secondary school at the 12th grade. We carried out the applications on the experimental and control groups by ourselves. During the research, in the scope of this lesson, the students have done the experiments of molecule models of alcohols and ethers, molecule models of aldehydes and ketones, molecule models of carboxylic acids and esters, maleic and fumaric acid synthesis and iodoform synthesis that are related to functional groups.

For ethical reasons, students were introduced orally to the purpose of the study and notified about how and what data would be obtained. They were informed that participation was voluntary and they were able to withdraw at any time without providing a reason.

\subsection{Data collection tools}

The data were collected through functional group term tests and semi-structured interviews during the research.

\subsubsection{Functional Groups Term Tests (FGTTs)}

FGTTs were created by adapting the vocabulary tests by the researchers. Vocabulary tests are assessment and evaluation tests that have been developed by the researchers to assess the knowledge of vocabulary and/or concept (Martorella, 1986). In those tests, the meaning of the word and its relation to the topic are asked to the students. In the term tests that were created in line with these tests, the functional group terms of each experiment were given to 
the students and the meaning and their relation to the topic were asked. The main purpose here was to assess the students' knowledge of concepts related to functional groups, through term tests. When the terms make sense in human mind and an interrelation is established among the terms, they turn into concepts (Vygotsky, 1986). The concepts are the reflections of objects, ideas and situations in human mind. Terms are the expressions of scientific concepts in language and are the smallest units with meanings. In other words, terms are possibly shown as the scientific symbols of concepts, which determine their personal meanings (Martin, 1985; Sarma, 2006). The student makes sense of the term and turns it into a concept by finding the relation of the term, which is in the term tests, both with the topic and the other terms.

While developing the FGTTs, we considered all the experiments and formed five different term tests. Each test included the related terms in the experiment and the other terms that were possibly related to these terms.

Table 2. Sample experiment, its aim, process and terms

\begin{tabular}{|c|c|c|c|}
\hline $\begin{array}{l}\text { Sample } \\
\text { experiment }\end{array}$ & Aim of the experiment & $\begin{array}{l}\text { The process of the } \\
\text { experiment }\end{array}$ & $\begin{array}{l}\text { The terms and molecules that should be } \\
\text { known }\end{array}$ \\
\hline $\begin{array}{l}\text { Maleic and } \\
\text { fumaric } \\
\text { acid } \\
\text { synthesis } \\
\text { experiment }\end{array}$ & $\begin{array}{l}\text { The aim of this experiment is to } \\
\text { teach the students } \\
\text { stereoisomerism, optical } \\
\text { isomerism and geometric } \\
\text { isomerism, chiral and achiral } \\
\text { structures, nucleophilic addition } \\
\text { reaction and the concepts of } \\
\text { nucleophile, electrophile with } \\
\text { fumaric acid synthesis from } \\
\text { maleic anhydride. }\end{array}$ & $\begin{array}{l}\text { In this experiment, the } \\
\text { maleic acid is prepared } \\
\text { by adding water in } \\
\text { anhydride. At the } \\
\text { second step, the maleic } \\
\text { acid is turned into } \\
\text { fumaric acid by being } \\
\text { heated under condenser } \\
\text { and with the addition of } \\
\text { concentrated } \mathrm{HCl} \text {. }\end{array}$ & $\begin{array}{l}\text { Acid regulation, anhydride bond, } \\
\text { carboxylic acid, chiral, crystal, } \\
\text { diastereomer, dipole-dipole attractions, } \\
\text { electrophile, elimination, enantiomer, } \\
\text { fumaric acid, geometric isomerism, } \\
\text { hydrolysis, maleic acid, maleic } \\
\text { anhydride, melting point, nucleophile, } \\
\text { optical isomerism, positional isomerism, } \\
\text { physical property, solubility, substitution } \\
\text { reaction, structural isomerism, van der } \\
\text { Waals bond. }\end{array}$ \\
\hline
\end{tabular}

As an example, the terms and molecules that are necessary to be known about maleic and fumaric acid synthesis are given in the Table 2. To better understand the reason why these terms were chosen about the experiment, the aim and process of the experiment were demonstrated briefly in Table 2 .

In FGTTs, based on the experiments, 117 terms, 23 of which are related to molecule models of alcohols and ethers, 25 are related to molecule models of aldehydes and ketones, 28 are related to molecule models of carboxylic acids and esters, 24 are related to maleic and fumaric acid synthesis, 17 are related to iodoform synthesis; have been presented to the students. We applied the FGTTs as pretest before the experiments and posttest following the experiments on experimental and control groups. Posttest were applied on experimental group at the end of the game OrCheTaboo.

The content validity of the test was achieved through the analysis made by two qualified academics in organic chemistry. The tests were scored according to the categories shown in the Table 3. Additionally, the maximum total score that was possible to get from the tests was 351 .

Table 3. The scoring of the term tests

\begin{tabular}{ll}
\hline Category & Scoring \\
\hline I do not know the meaning. & 0 \\
I have heard about the term before but I do not remember. I can relate it to the & 1 \\
following terms... & 2 \\
I know the term. The meaning and the relation of it to the topic are as follows... & 2 \\
\hline
\end{tabular}

To provide the reliability of the scoring, we scored the data at different times. A percentage agreement was calculated according to the results of the scorings, so we found as .93. As this is a higher rate from .75 , the analysis that has been done is reliable and within the "perfect agreement" rates (Fleiss, Levin, \& Paik, 2003).

\subsubsection{Semi-structured interview}

During the research, we have carried out semi-structured interviews to find out if the game OrCheTaboo is effective in learning the concepts about functional groups. We conducted the interviews with each student in experimental group after the experiments and OrCheTaboo game. During the interview, five open-ended questions were asked to 
the students. Each interview has lasted for 20-25 minutes. The interviews were subjected to content analysis by being turned into transcripts by researchers. We coded the open-ended questions separately and categorized them. For the reliability of the analysis, the agreement rate of the researchers were checked and found out as .94.

\subsection{Data analysis}

We applied the FGTTs, which were the quantitative data of the research, as pretest before the experimental study and as posttest at the end of it. The collected data were analyzed through arithmetic mean, standard deviation and independent samples t-test by using SPSS 15.0 statistics package software. Moreover, the significance level was taken as $\mathrm{p}<.05$ in the table scores. As there was a difference between the experimental and the control group in the posttest; we used Cohen's $d$ to determine the effect size causing that difference and eta-squared $\left(\eta^{2}\right)$ to find out the power of relation. For the qualitative data of the research, while the four of the interview questions which were asked to the students were being subjected to content analysis, descriptive analysis was used in one question. The results of the content analysis were given as frequency (f) and percentage (\%).

\subsection{The OrCheTaboo game and the application process}

The aim of OrCheTaboo is to describe a certain term according to the rules of the game by not using the forbidden terms to the team-mates. The more terms one can correctly describe, the more the team has the chance to win the game. During the research, the OrCheTaboo game has been played with the experimental group. First of all, certain experiments have been carried out during the Organic Chemistry Laboratory lesson throughout a 10 weeks' time. At the end of this period, the students have been played the OrCheTaboo game for 2 weeks. During the game, the experimental group students have been separated into two teams. The teams have consisted of 6 groups. Two of these groups have consisted of 6 members and the others have consisted of 5 members. The OrCheTaboo game was played in the Laboratory environment as follows: The students were asked to describe a term related to the topic of functional groups, without using the forbidden terms. They had two minutes for the description. On the taboo cards that were prepared for the game, there were 3-5 forbidden terms right under the target term that was asked to be described. When the time started, one of the members of the group tried to describe the term to the other members of the group. If he/she used a forbidden term while describing or if he/she could not describe the term, it was cancelled and they went on with another target term. Everybody could pass for maximum one time. The group that found the more target terms correctly won the game.

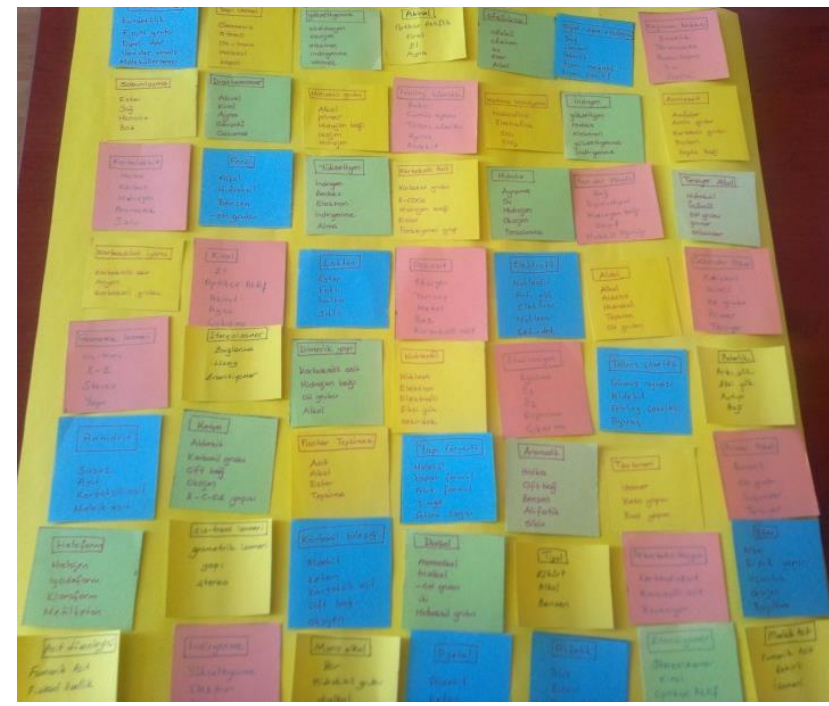

Figure 1. Taboo cards in OrCheTaboo game

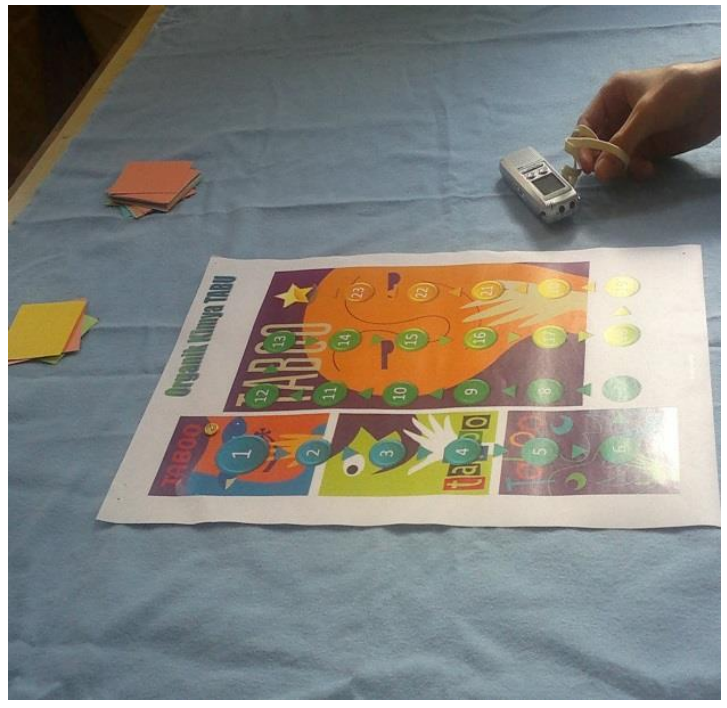

Figure 2. OrCheTaboo game table

There were 58 target terms prepared for the game. These terms were also included in the FGTTs. The OrCheTaboo cards containing target and forbidden terms are shown in Figure 1. Starting from the number 1, which was shown on the game table, both of the groups proceed as much as the number of the terms they described correctly, the group who reached the last point, won the game and the game was over. The game table is shown in Figure 2. Additionally, some examples of OrCheTaboo cards included target and forbidden terms are represented in Figure 3. 


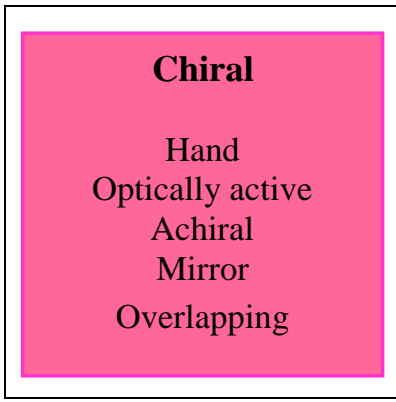

\section{Findings}

In this section, the research findings and the comments on those findings have been analyzed considering the data acquired from the sub problems of the research to get an answer to the research problem which is "Does the game OrCheTaboo has an effect on the students' learning of the concepts related to functional groups?" Accordingly, the quantitative data acquired from FGTTs and the qualitative data acquired from semi-structured interview, the findings that have come out as the result of the analysis of those data and the comment on those data are respectively presented.

\subsection{The findings related to the first sub problem of the research}

It has been analyzed if there is an academic difference between experimental and control groups, through the pretest that has been applied before exploring the effect of the game OrCheTaboo on students' learning the concepts related to functional groups (Table 4).

Table 4. The t-test results of the experimental and control groups related to FGTTs' pretest scores

\begin{tabular}{|c|c|c|c|c|c|c|c|}
\hline Test & Group & $\mathrm{N}$ & $\overline{\mathrm{X}}$ & SD & $\mathrm{df}$ & $\mathrm{t}$ & $\mathrm{p}$ \\
\hline & Control & 30 & 161.24 & 37.44 & 60 & -1.59 & $0.12 *$ \\
\hline Pretest & Experimental & 32 & 182.61 & 63.87 & & & \\
\hline
\end{tabular}

$* \mathrm{p}<.05$

As shown in Table 4, the mean scores that control $(\overline{\mathrm{X}}=161.24)$ and experimental $(\overline{\mathrm{X}}=182.61)$ groups got from the pretest application of functional group term tests are close to each other.

There have not been a statistically significant difference determined between the mean of the groups that have been selected according to the result of the independent samples $t$-test $(t=-1.59, p(.12)>.05)$. This finding indicates that the two groups are equal to each other and the experimental study is ready to start. Besides, the mean scores the groups got from each pretest of the FGTTs are as in Figure 3 and Figure 4.

\subsection{The findings related to the second sub problem of the research}

To find out if there has been a difference in the students' learning of the concepts related to the subject of functional groups as a result of activity carried out with the game OrCheTaboo, a posttest has been applied to the both groups. According to the t-test results, Table 5 shows that there have been a significant difference determined between the mean scores the experimental and control groups got from FGTTs $(\mathrm{t}=-5.03, \mathrm{p}(.00)<.05)$. This result indicates that the game OrCheTaboo has developed the students' learning of concepts related to functional groups.

Table 5. The t-test results of control and experimental groups related to FGTTs' posttest scores

\begin{tabular}{llllllll}
\hline Test & Group & $\mathrm{N}$ & $\overline{\mathrm{X}}$ & $\mathrm{SD}$ & $\mathrm{df}$ & $\mathrm{t}$ & $\mathrm{p}$ \\
\hline \multirow{2}{*}{ Posttest } & Control & 30 & 232.78 & 65.99 & 60 & -5.03 & $.00^{*}$ \\
\cline { 2 - 5 } & Experimental & 32 & 334.83 & 90.94 & & & \\
\hline
\end{tabular}

$* \mathrm{p}<.05$

On the other hand, eta squared $\left(\eta^{2}\right)$ and Cohen's $d$ values have been examined by using the data that are acquired in the posttest for the purpose of determining the effect size of OrCheTaboo, which is an active learning activity, upon the learning of functional groups. While Cohen's $d$ value indicates the effect size that is calculated according to the group mean differences; eta squared $\left(\eta^{2}\right)$ value shows the power of relationship that is calculated according to the correlation between the dependent and independent variables (Cohen, 1988; Maxwell \& Delaney, 1990). The effect 
size coefficient (Cohen's $d$ ) between the FGTTs scores of both groups was calculated as 1.30. Regardless of the sign of Cohen's $d$ value; the size of the effect is respectively interpreted as small, medium and large $(.20, .50$ and .80$)$ (Cohen, 1992). This value shows that the OrCheTaboo game has a "large" effect upon learning the terms in functional groups. Besides, the eta squared $\left(\eta^{2}\right)$ value was calculated as .29 (Ellis, 2010). Accordingly, we could suggest that $29 \%$ of the variance belongs to the posttest scores of FGTTs emerge depending on learning with the game OrCheTaboo.

\subsection{The findings related to the third sub problem of the research}

In the third sub problem of the research, mean scores of the posttest scores that the experimental and control groups got from a test related to the each experiment of FGTTs have been compared to find out the effectiveness of the game OrCheTaboo. As a result, it is clear that, following the activity, the mean scores of both experimental and control groups have increased, however, the increase in the scores of the experimental group has been more than the control group (see Figure 4 and Figure 5).

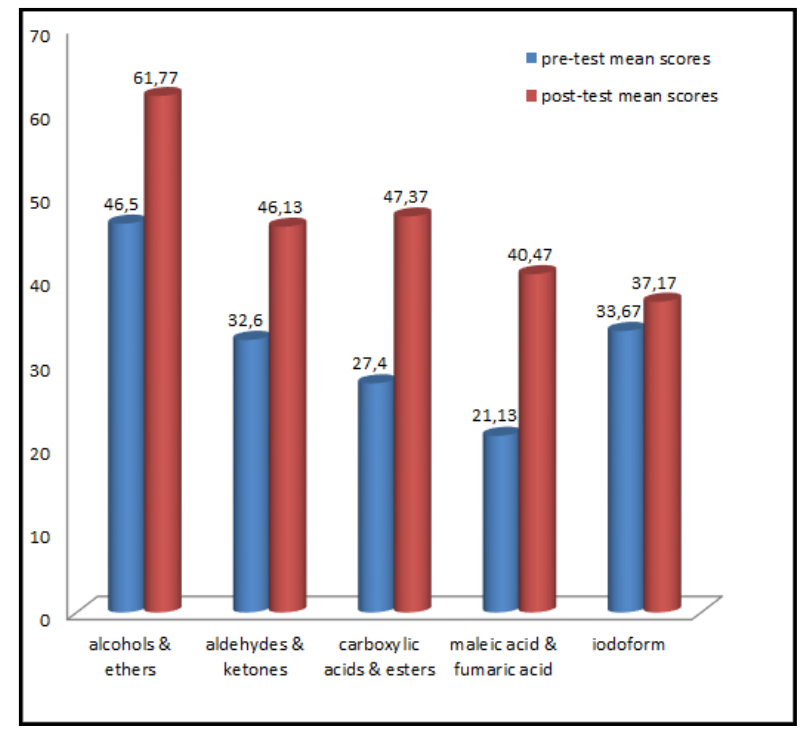

Figure 4. Mean scores of control group pretest-posttest

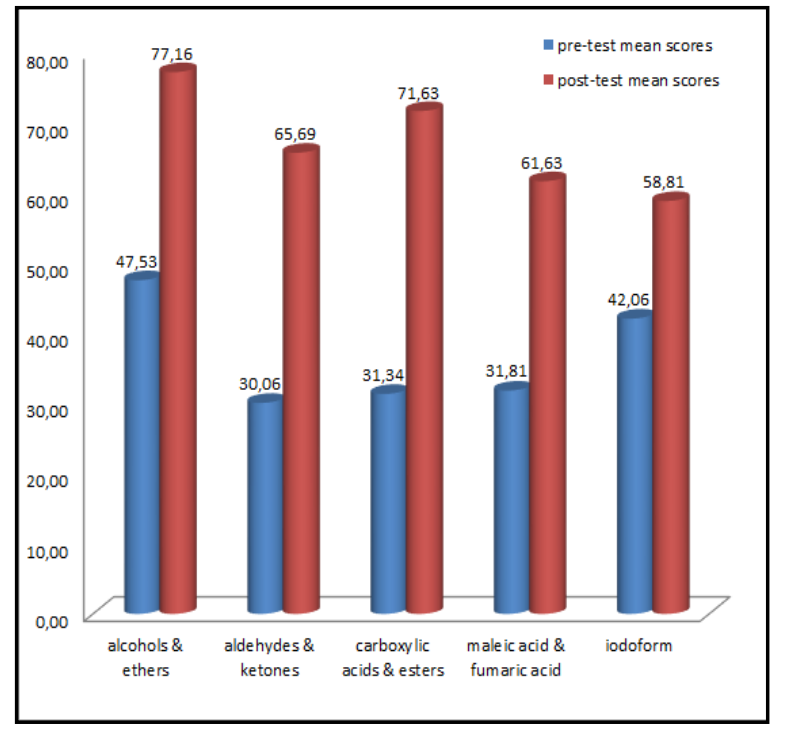

Figure 5. Mean scores of experimental group pretest-posttest

According to the Table 6, when the increase difference of the mean scores the experimental and control groups got from FGTTs related to the each experiment has been analyzed and found out to be 15.51 for the Molecule Models of Alcohols-Ethers experiment; 19.56 for the Molecule Models of Aldehydes-Ketones experiment; 24.33 for the Molecule Models of Carboxylic acids-Esters experiment; 21.16 for the Maleic acid-Fumaric acid Synthesis experiment and 21.51 for the Iodoform Synthesis experiment.

Table 6. The posttest mean scores of experimental and control groups got from each test related to experiments of FGTTs

\begin{tabular}{|c|c|c|c|c|c|c|c|}
\hline Name of the experiment & Group & $\mathrm{N}$ & $\overline{\mathrm{X}}$ & SD & $\mathrm{df}$ & $\mathrm{t}$ & $\mathrm{p}$ \\
\hline \multirow{2}{*}{$\begin{array}{l}\text { Molecule models of } \\
\text { alcohols and ethers }\end{array}$} & Control & 30 & 61.73 & 3.84 & \multirow[t]{2}{*}{60} & \multirow[t]{2}{*}{-3.41} & \multirow[t]{2}{*}{$.01 *$} \\
\hline & Experimental & 32 & 77.24 & 2.52 & & & \\
\hline \multirow{2}{*}{$\begin{array}{l}\text { Molecule models of } \\
\text { aldehydes and ketones }\end{array}$} & Control & 30 & 46.13 & 17.06 & \multirow[t]{2}{*}{60} & \multirow[t]{2}{*}{-4.29} & \multirow[t]{2}{*}{$.00 *$} \\
\hline & Experimental & 32 & 65.69 & 18.65 & & & \\
\hline \multirow{2}{*}{$\begin{array}{l}\text { Molecule models of } \\
\text { carboxylic acids and esters }\end{array}$} & Control & 30 & 47.26 & 19.84 & \multirow[t]{2}{*}{60} & \multirow[t]{2}{*}{-4.32} & \multirow[t]{2}{*}{$.00 *$} \\
\hline & Experimental & 32 & 71.59 & 24.10 & & & \\
\hline \multirow{2}{*}{$\begin{array}{l}\text { Maleic and fumaric acid } \\
\text { synthesis }\end{array}$} & Control & 30 & 40.47 & 17.18 & \multirow[t]{2}{*}{60} & \multirow[t]{2}{*}{-4.54} & \multirow[t]{2}{*}{$.00^{*}$} \\
\hline & Experimental & 32 & 61.63 & 19.34 & & & \\
\hline \multirow[t]{2}{*}{ Iodoform synthesis } & Control & 30 & 37.18 & 17.00 & \multirow[t]{2}{*}{60} & \multirow[t]{2}{*}{-3.99} & \multirow[t]{2}{*}{$.00 *$} \\
\hline & Experimental & 32 & 58.69 & 24.58 & & & \\
\hline
\end{tabular}

$* \mathrm{p}<.05$ 
As a result of the independent t-tests applied to find out if these increases are statistically significant or not, they have been found out to be significant (respectively, $\mathrm{t}=-3.41, \mathrm{p}(.01)<.05 ; \mathrm{t}=-4.29, \mathrm{p}(.00)<.05 ; \mathrm{t}=-4.32, \mathrm{p}(.00)<.05 ; \mathrm{t}=-4.54$, $\mathrm{p}(.00)<.05 ; \mathrm{t}=-3.99, \mathrm{p}(.00)<.05)$. In accordance with this result, it is possible to state that the activity of the game OrCheTaboo makes it easier to learn the terms included in each experiment.

\subsection{The findings related to the fourth sub problem of the research}

Within the scope of the fourth sub problem of the research, the students have been asked about their opinions on the activity of the game OrCheTaboo. During the interview, five open-ended questions have been asked to the students. While content analysis has been applied to four of those questions, descriptive analysis has been used for one question. First of all, the findings that have come out as a result of the content analysis are presented respectively in categories through frequency and percentage.

During the interviews, first of all, the question "Do you think that the activity OrCheTaboo which has been carried out in organic chemistry laboratory helps you learning the concepts related to the functional groups?" has been asked to the students. Through this question, it has been tried to be found out if the game OrCheTaboo is effective on the students' learning the concepts related to functional groups. According to the findings, 91\% of the students (f: 29) think that it helps learning the concepts related to the functional groups, $9 \%$ (f: 3 ) of them think that it does not help (see Figure 6).

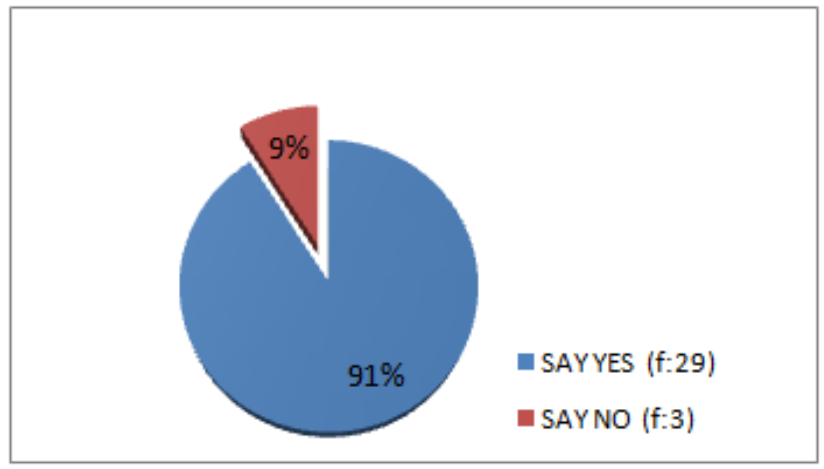

Figure 6. The number of students who think that the game OrCheTaboo is effective on learning

Table 7. The frequency (f) and percentage (\%) distribution of the answers given to the question "What contributions does the game OrCheTaboo make to your learning of the concepts?"

\begin{tabular}{llll}
\hline Category & f & $\%$ & Sample student opinion \\
\hline Retention in & 22 & 33.3 & $\begin{array}{l}\text { It had a reinforcing effect. It helped us to practice and review more. Thus it provided } \\
\text { our knowledge to be permanent }(S .1) . \\
\text { learning }\end{array}$ \\
& $\begin{array}{l}\text { Making an effort while trying to describe the terms, made those terms memorable } \\
\text { (S.5). }\end{array}$
\end{tabular}

Fun learning $\quad 20 \quad 30.3$ The activity OrCheTaboo has both made the lesson more entertaining and eased my learning and perception of the subject. The concepts that I was trying to memorize and that were boring before became fun and easily learnable with the game OrCheTaboo (S.8).

We played the game with my teammates, having fun. Thus, my perception was better during the lesson (S.15).

Association between the concepts

Increasing the motivation
1421.2 We could express the concepts in sentences. We could explain their outstanding characteristics and their relation to each other to describe them (S.14).

I especially learned how to reach a concept by following different ways while describing the concept (S.11).

1015.2 It had an important role in motivating us. We had to learn to win the game. During the times out of the game, instead of chatting with our teammates, we learned those concepts. It motivated us to study (S.18).

While describing the concepts, we were in a continuous competition. This motivated me to describe the terms better. It also provided the active listening... (S.6). 
With reference to the findings, questions about how the game OrCheTaboo contributes to the learning of concepts have been asked to students. When the answers given by the students have been analyzed, four separate categories come out (see Table 7).

When these findings have been analyzed, we found out that the category retention in learning has the most percentage (33.3\%). This may result from the fact that the students have the chance to reinforce the concepts by reviewing them during the activity OrCheTaboo. Among many students, the category fun learning (30.3\%) has come out. As the students have a fun and live class with the activity OrCheTaboo, they have participated in the learning environment actively and they have been more eager to learn. Another category that has come out from the findings has been association between the concepts (21.2\%). The game OrCheTaboo is based on describing, so it develops the students' knowledge of concepts related to functional groups. The last finding that has been found out through this question is the category of increasing the motivation. It has been determined that the students are in a competition to win over the opposing team during the game OrCheTaboo and thus the game increases their motivation and also motivate them to study the concepts out of the game. Another question that has been asked to the students during the interviews is what difficulties they had during the game OrCheTaboo while describing the terms. When we analyzed the answers to this question, most of the answers are about the difficulty in association between the concepts $(24.2 \%)$ and scientific description (22.6\%) (see Table 8 ). This might result from the fact that the students are not able to comprehend the molecular structures in organic chemistry and they are not able to classify their similar and different characteristics. Furthermore, the students have based the reason why they are not able to describe the terms, on their lack of knowledge about the subject of functional groups. Thus it is possible to state that the students have difficulty while learning the subjects of organic chemistry.

Table 8. The frequency (f) and percentage (\%) distribution of the answers given to the question "What difficulties do you have during the game OrCheTaboo while describing the term?"

\begin{tabular}{|c|c|c|c|}
\hline Category & $\mathrm{f}$ & $\%$ & Sample student opinion \\
\hline \multirow{2}{*}{$\begin{array}{l}\text { Difficulty in } \\
\text { association } \\
\text { between the } \\
\text { concepts }\end{array}$} & \multirow[t]{2}{*}{15} & \multirow[t]{2}{*}{24.2} & $\begin{array}{l}\text { I had the most difficulty in associating. I reflected on how to reach a concept } \\
\text { from different ways during this game (S.26). }\end{array}$ \\
\hline & & & $\begin{array}{l}\text { Even though I knew about a term, I was not able to use it in a sentence, I felt } \\
\text { like I would be wrong. This was because of my incapability to associate the } \\
\text { term to another term (S.7). }\end{array}$ \\
\hline \multirow{2}{*}{$\begin{array}{l}\text { Difficulty in } \\
\text { scientific } \\
\text { description }\end{array}$} & \multirow[t]{2}{*}{14} & \multirow[t]{2}{*}{22.6} & $\begin{array}{l}\text { I tried to describe by giving examples from daily life. Nevertheless, I had } \\
\text { difficulty in describing through chemistry language (S.17). }\end{array}$ \\
\hline & & & $\begin{array}{l}\text { Sometimes I made it difficult for my friends to understand as I was not able to } \\
\text { describe the term that I knew (S.3). }\end{array}$ \\
\hline Lack of time & 12 & 19.4 & $\begin{array}{l}\text { We had to describe too many terms in a certain time and it was difficult } \\
\text { (S.12). }\end{array}$ \\
\hline \multirow[t]{2}{*}{$\begin{array}{l}\text { Lack of } \\
\text { knowledge }\end{array}$} & \multirow[t]{2}{*}{11} & \multirow[t]{2}{*}{17.7} & $\begin{array}{l}\text { Even though I had heard in class, it was difficult to describe a concept that I } \\
\text { did not really know. For example the dimeric structure term. I tried to } \\
\text { describe by describing the forbidden terms first (S.13). }\end{array}$ \\
\hline & & & $\begin{array}{l}\text { I realized that, the fact that I am not sufficient in the subject functional } \\
\text { groups made it difficult for me to describe (S.28). }\end{array}$ \\
\hline \multirow[t]{2}{*}{$\begin{array}{l}\text { The forbidden } \\
\text { terms }\end{array}$} & \multirow[t]{2}{*}{10} & \multirow[t]{2}{*}{16.1} & $\begin{array}{l}\text { The biggest difficulty was caused by the forbidden terms. However, I tried to } \\
\text { make my friends find them by describing them one by one (S.5). }\end{array}$ \\
\hline & & & $\begin{array}{l}\text { I struggled to describe without using the forbidden terms. First of all, I } \\
\text { described the characteristics of the forbidden terms }(S .25) \text {. }\end{array}$ \\
\hline
\end{tabular}

When the answers were given to the question "Do you consider yourself sufficient during the game OrCheTaboo while describing the term?" by the experimental group students, we found out that $53.0 \%$ (f: 17 ) of them consider themselves sufficient (see Figure 7).

Following the question, the students have been asked about their opinions why they consider themselves sufficient or insufficient. The answers given to this question have been presented in categories in Table 9. According to the findings, the students have mostly talked about the ability of expressing $(22.8 \%)$ among the answers given by the students who consider themselves sufficient. Thus it is possible to state that the game OrCheTaboo is effective on 
students' developing their chemistry language. Moreover, with the category interested in the lesson (14.3\%), we determined that the ones who are interested in the organic chemistry laboratory consider themselves more sufficient in describing terms. The categories that have come out as a result of the answers given by the ones who consider themselves insufficient to the question why they consider themselves insufficient are, the incapability of associating the terms and lack of self-confidence.

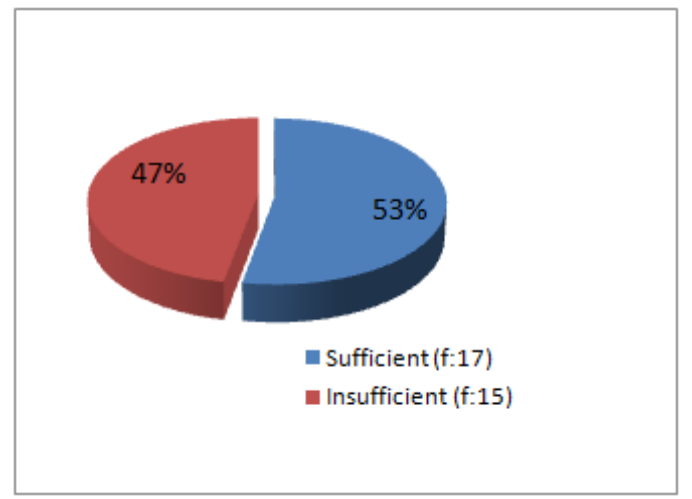

Figure 7. The percentage distribution of students who consider themselves sufficient or insufficient

Table 9. The frequency (f) and percentage (\%) of the answers given to the question "Why do you consider yourself sufficient or insufficient in the game OrCheTaboo?"

\begin{tabular}{|c|c|c|c|c|}
\hline \multicolumn{2}{|c|}{ Category } & $\mathrm{f}$ & $\%$ & Sample student opinion \\
\hline \multirow{4}{*}{ 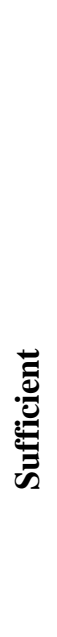 } & $\begin{array}{l}\text { Having the } \\
\text { knowledge }\end{array}$ & 14 & 20.0 & The game taboo showed me if I know the terms in functional groups or not (S.29). \\
\hline & $\begin{array}{l}\text { The ability to } \\
\text { associate }\end{array}$ & 8 & 11.4 & $\begin{array}{l}\text { I think I was able to describe the terms sufficiently. For example one of the terms I } \\
\text { described was ketone. First of all, I tried to describe through alcohol and then I } \\
\text { made them find seconder alcohol. Following that, making them find the forbidden } \\
\text { term Oxygen, I told them that it comes out with the oxidation of the seconder } \\
\text { alcohol, and then they easily understood. I think I describe the relation between the } \\
\text { terms well by reflecting about the terms (S.9). }\end{array}$ \\
\hline & $\begin{array}{l}\text { Ability of } \\
\text { expressing }\end{array}$ & 16 & 22.9 & $\begin{array}{l}\text { The terms were complicated for me but I consider that I was able to describe them } \\
\text { one by one in sentences (S.14). }\end{array}$ \\
\hline & & & & $\begin{array}{l}\text { While describing the term, instead of using entirely different terms, describing by } \\
\text { making an analogy was easier and more understandable. For example, for the term } \\
\text { aliphatic, first I described the chain structure and then I told that the carbon atoms } \\
\text { are connected to each other through chain structure (S.19). }\end{array}$ \\
\hline \multirow{4}{*}{ 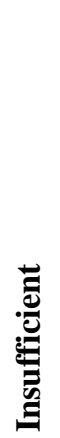 } & $\begin{array}{l}\text { Interested in the } \\
\text { lesson }\end{array}$ & 10 & 14.3 & $\begin{array}{l}\text { As I like the organic chemistry lesson, I am able to give more attention to the } \\
\text { lesson. Thus I consider myself sufficient in describing the terms (S.12). }\end{array}$ \\
\hline & & & & $\begin{array}{l}\text { I did not have difficulty while both describing and trying to find the term as I like } \\
\text { everything about organic chemistry (S.23). }\end{array}$ \\
\hline & $\begin{array}{l}\text { Lack of } \\
\text { self-confidence }\end{array}$ & 10 & 14.3 & $\begin{array}{l}\text { To be able to describe the terms, I must have a good knowledge of organic } \\
\text { chemistry; however, I do not trust myself in that (S.8). }\end{array}$ \\
\hline & $\begin{array}{l}\text { Inability to } \\
\text { associate }\end{array}$ & 12 & 17.1 & $\begin{array}{l}\text { I am not able to associate some terms to others. For example while describing the } \\
\text { term, I can imagine it but I do not have an idea how to describe it through the other } \\
\text { concepts (S.23). }\end{array}$ \\
\hline
\end{tabular}

Another interview question was "Giving an example of the terms in the game, explain how you described it to your friends." Through this question, how the students have expressed the relation of the terms to the organic chemistry subjects during OrCheTaboo and how they have used the chemistry language while explaining the term have been analyzed. According to the results of the descriptive analysis, we determined that, while describing a term, the students have considered the structural characteristics of the molecules and reactions, based on the similar and 
different characteristics of the other terms (see Table 10). For example, while a student was describing the term phenol, she put forward the molecular structure of the term and then described the term considering its structural characteristics and reactions. At this point, she has made use of the distinctive and non-distinctive characteristics. Another student has made use of its reactions while describing carboxylic acid. Besides, realizing their own mistakes about the terms they used while describing, the students tried to correct them.

Table 10. The terms the students described and their ways of description

\begin{tabular}{ll}
\hline The term & The way of description \\
\hline Phenol & $\begin{array}{l}\text { I tried to describe benzene by saying the ring structure which contains pi bonds, first. When } \\
\text { they found benzene, I told them to bond a nucleophilic group to this structure. I had them } \\
\text { found what this nucleophilic group is. At first, they could not guess. I told them to resolve } \\
\text { water, and then they found the hydroxyl group. They guessed the term as alcohol. I said it was } \\
\text { not alcohol and reminded them that there is double bond in the carbon to which the hydroxyl } \\
\text { group is bonded and they found phenol(S.2) } \\
\text { I asked which ion is available in basic environment. They answered -OH. I asked them the } \\
\text { specific name of -OH. They answered hydroxyl group. I asked hydroxyl group is the functional } \\
\text { group of what. They answered alcohol (S.21). } \\
\text { Chiral } \\
\text { I told them that different atom groups are bonded to the carbon atom. I asked what kind of a } \\
\text { carbon atom it is. They answered optically active. Then I told them that their reciprocal image } \\
\text { is not the same. Then I told them to combine these two characteristics. They found the term } \\
\text { chiral (S.27). }\end{array}$ \\
Carboxylic & $\begin{array}{l}\text { I asked them what comes out as a result of the oxidation of ketone. My friends could not } \\
\text { answer the question. Then I realized that I described wrong. I asked them what comes out as a } \\
\text { result of the oxidation of aldehyde. They answered carboxylic acid (S.15). }\end{array}$
\end{tabular}

\section{Discussion and Conclusions}

This research, which has been organized as an experimental study, has been carried out to find out if the game OrCheTaboo has an effect on the university students' learning the concepts about functional groups in Organic Chemistry. With reference to the findings that have been reached towards this aim, there is no significant difference between the FGTTs' pretest scores of experimental and control groups. This reveals that the groups are similar and the experimental process is applicable. In the research, when the FGTTs' posttest mean scores of the experimental group is compared to the control group's, a significant difference has been determined and this difference has been found out to be in favour of the experimental group on whom the activity of the game OrCheTaboo has been applied. Besides, the mean scores of each FGTT have also been found out to be in favour of experimental group and they are significant. The findings that have been reached through the interview questions about the activity of the game OrCheTaboo support the results of quantitative analysis as well. According to this, it is clear that most of the students (f: $29 ; 91.0 \%$ ) learn the concepts about functional groups more effectively through the game OrCheTaboo. Considering these findings, we can state that the game OrCheTaboo plays an effective role in the learning of the concepts about the subject of functional groups. Our results are parallel to the results of the research that Olimpo et al. (2010) carried out about the effectiveness of the Taboo game on biology students. The researchers have prepared a Biology Taboo Wictionary which contains the concepts they learned in the Introductory Biology lesson and consists of 78 cards, throughout a semester. The data of the questionnaire that they applied on the students following the game show that more than $70 \%$ of the students think that the Taboo game is helpful for the learning of basic biology terms. A similar finding is also available in the study of Taşdelen, Köseoğlu, Özdem and Demirdöğen (2010), in the literature related to the Taboo game. Accordingly, they discovered that the knowledge of the students about Nature of Science (NOS) has increased with the Taboo game that was applied at the end of the semester. Additionally, they stated that this activity was helpful to enhance and evaluate students' views on NOS aspects they learned throughout the course. That, there are studies available about the effectiveness of the Taboo game in the literature support our results (Brooks \& Tollison, 2009; Harmon \& Crutcher, 2008; Merwin, 2003; Türk, Güngör, \& Karaaslan, 2011).

In the qualitative findings that have been acquired about how the game OrCheTaboo contributes to the learning of the concepts of the experimental group students, the students (f: $22 ; 33.3 \%$ ) have mostly stated that it provides a permanent learning. Especially through the game OrChetaboo, the students have stated that they have learned the chemistry terms by reviewing during the game. Capps (2008) has stated that this game is effective on the learning of 
basic chemistry concepts because of its consolidating characteristic. Harmon and Crutcher (2008) have got the result that the math students comprehend the math terms better by using the Taboo cards in their research. Additionally, Merwin (2003) has revealed that the activity she developed by using the Taboo game has been quite effective on the $71 \%$ of the students, who study in the department of psychology, to better comprehend the concepts related to the class. Besides, we have identified that the students (f: 20;30.3\%) learn the concepts better during fun learning. Not only the students have carried out the process based experiments that are classically applied in organic chemistry laboratory, but also they have reinforced the terms in the experiments through OrCheTaboo. As this study contains the game OrCheTaboo besides the classical experiments, it is both a group game and a fun activity. Knudtson (2015) has determined that the students are able to memorize many concepts more easily by having fun with the card game he prepared about the functional groups. Likewise, with the board game, Compoundica and the card games, Periodica and Groupica that he has prepared, Bayir (2014) has found out that 250 students have learned the basic chemistry concepts, having fun and that the learning is permanent. Samide and Wilson (2014) have aimed to make it easier to learn the complicated concepts through the games that they have prepared based on the game based approach in analytical chemistry and organic chemistry. Through the games that have been developed in line with this aim, the students have not only had fun but also had developed a deeper comprehension about the subject by using different ways of thinking. Duffy (2006) has stated that activities which lead the students to different ways of thinking are necessary for the realization of the conceptual comprehension. Ziv (1988) has emphasized that playing the game is funny and an important element in learning. Randel and Morris (1992) have expressed that the games can be used as a teaching method, thinking that they contribute to the reinforcement of the knowledge and the classes to be fun. By looking at some findings about students (f: $10 ; 15.2 \%$ ), another effect of teaching through game is that games have a motivation increasing characteristic. Some of the students have tried to describe the concepts about the subject that they are likely to come across to each other, out of the class to be able to win the game. Therefore, they both have made use of their spare time and they have had a higher motivation to learn. Hence, we can say that the game OrCheTaboo helps the concepts to stick in mind due to its characteristics of fun learning and motivation increasing like the several other teaching through game activities. The studies in the literature show that games make learning permanent by increasing the motivation, similar to our findings (Costa, 2007; Franco-Mariscal, Oliva-Martinez, \& Bernal-Marquez, 2012; Garris, Ahlers, \& Driskell, 2010; Kavak, 2012). With reference to the findings about students (f: $14 ; 21.2 \%$ ), another important contribution of the game OrCheTaboo is that it helps the learning of both the concept and the subject as a whole by associating the concepts to other concepts. While the students are describing the term or while they are listening to the description, they have turned the term into a concept by reflecting about the relation of the terms they come across during the game, with the other terms and what distinctive and similar characteristics they have. Likewise, the category of the ability to associate the concepts to others (f: $8 ; 11.4 \%$ ) also takes place in the findings about why the students find themselves sufficient while describing the concept during the game OrCheTaboo. Nakhleh (1992) has stated that, for the science teaching, the teacher has to be at least at the conceptual level from the cognitive levels. Besides, she has expressed that the concepts are the whole of the propositions; however, they will turn into concepts when their relations in the subject are given. Thus, we can state that the students are able to experience the concept developing process through the game OrCheTaboo. For example, while student is going into the process of describing, which is one of the concept developing processes, by describing an unknown concept via the known concepts, he/she is going into the distinction process by thinking about and telling the similar or distinctive characteristics with the other concepts. Additionally, while describing the terms, we can state that they have the opportunity to develop their concepts about the subject by using the processes of generalization, induction and deduction. Although some of the students have stated that the game OrCheTaboo helps associating the concepts to others, when some of the statements of the students who find themselves insufficient (f: $15 ; 47 \%$ ) are considered, it is clear that they relate the reason of that to the same category, which is inability to associate the concepts. In this case, while some of the students are able to associate the term to another term or in the subject while describing the term, some of the students have difficulty in doing the same. The reasons why the students have difficulty might be that they are likely to come across with unknown terms frequently in organic chemistry, that the characteristics of the terms are sophisticated and thus the students are eager to memorize the term rather than comprehending it. Besides, this may result from the students' lack of knowledge or misunderstanding during the process of concept developing. Vygotsky (1986) states that as many characteristics a concept has, it takes as long time to learn it. During the game OrCheTaboo, the findings that have come out from the question what difficulties the students have had while describing the term, support our result. Some of the students (f: $11 ; 17.7 \%$ ) lack of knowledge while describing the term, and some of them (f: 14; $22.6 \%$ ) have difficulty in scientific description. Therefore, they are unable to give the relations of the concepts while describing them and suffer from lack of self-confidence. As a positive aspect of our result, it is possible to state that the game OrCheTaboo creates 
awareness about what the students lack on comprehending the concepts about the functional groups. Apart from these, another effective factor on the students' suffering from this difficulty is that there are forbidden terms in the game. Some of the students (f: $10 ; 16.1 \%$ ) have stated that it is difficult to describe the target term because of the forbidden terms. However, when the statements of the students are analyzed, we have found out that the students have tried to get the target terms found by making use of the forbidden terms. Merwin (2003) stated that forbidden terms force students to express the terms in their own words and implicitly test their knowledge. Forbidden terms encourage them to describe the concepts through various ways. While the students are describing the forbidden terms, they search for related, appropriate term and thus, they reflect through different ways. Duffy (2006) has stated that learning concepts depends on alternative ways of thinking. According to her, the students need to prefer viable and scientific pathways to comprehend the concepts in the subject. In this way, it is easier to learn the concepts related to the functional groups which are complicated and hard to learn. Therefore, we can state that the forbidden terms encourage the students to think creatively and scientifically. Another finding that has come out from the students (f: $17 ; 53.0 \%$ ) who find themselves sufficient while describing a term during the game OrCheTaboo is that it increases the ability of expressing. While describing a term in the game OrCheTaboo, the students develop their chemical language as well. Açıkgöz (2005) has stated that the games that serve for educational purposes can develop the language. The researchers have stated that using the scientific language has a central and significant role in conceptual comprehension (Brown, 2013; Fang, 2005; Lemke, 1990; Wellington \& Osborne, 2001). Gee (2005) has emphasized that the students need to know the scientific language to structure the concepts. Likewise, Vygotsky (1986) has stated that the scientific language and thought are one within the other in learning. Moreover, Duffy (2006) has taken the attention to the terminology representation in conceptual comprehension and has stated that it increases the comprehension of organic chemistry. According to her, the usage of the scientific language and chemistry terms together eases the comprehension of the concepts. In this direction, we can state that the students use the scientific language and additionally develop their chemistry language by communicating with each other through the game OrCheTaboo. In addition to these findings, the identification of the category of interested in the lesson in the statements of the students (f: 10;14.3\%) who find themselves sufficient is an important finding as well. The students who have a positive attitude towards the organic chemistry lesson have stated that they find themselves sufficient as they do not have difficulty in describing the term and they like the lesson. The studies have revealed that the students who like the organic chemistry lesson and who have curiosity and interested in this lesson have higher self-efficacy and are more successful in the class (Bhattacharyya, 2004; Bilir, 2009; Meyer, 2005; Wasacz, 2010).

Finally, a question about how they described the terms in the game OrCheTaboo has been asked to the experimental group students and tried to reveal which information about the term they will use and if they experience the conceptual process or not while describing the terms. We can say that the students describe the term mostly through its similar and distinctive characteristics compared to the other terms, their molecular structure and reactions, which is clear from the findings that have come out from the descriptive analysis of that question. At this point, we can state that the students make use of many of the conceptual development processes during the game OrCheTaboo and learn functional group terms by turning them into concepts through the game.

As a result, the game OrCheTaboo gives the opportunity to be in conceptual development processes like describing the terms to the students, identifying from the other terms or establishing its similar characteristics with the other terms, put their relation forward. Because of these characteristics, while turning the complicated and difficult terms related to the subject of functional groups into concepts and thus, their learning the game has a positive and active role.

\section{Implications}

First of all, the game OrCheTaboo can be used as a beneficial education tool both in the university and the high-school during the learning of functional groups. Moreover, it is possible to apply the game OrCheTaboo as an assessment activity following the lesson to see the conceptual comprehension and success in this subject. In the future studies, similar educational active learning activities may be developed for the different subjects of organic chemistry and their effectiveness may be evaluated. In the other fields of chemistry lesson (such as inorganic chemistry, analytical chemistry, biochemistry) like organic chemistry lesson in which the students have difficulty in learning, the motivation and success of the students in the class can be increased by making use of fun and teaching activities like Taboo game. 


\section{References}

Açıkgöz, K.Ü. (2005). Effective teaching and learning (6th ed.). Izmir: Education World Publications.

Angelin, M., \& Ramström, O. (2010). Where's ester? A game that seeks the structures hiding behind trivial names. Journal of Chemical Education, 87(4), 406-407. http://dx.doi.org/10.1021/ed800129r

Bhattacharyya, G. (2004). A recovering organic chemist's attempts at self-realization: How students learn to solve organic synthesis problems. Doctoral dissertation, Purdue University, West Lafayette, Indiana.

Bayir, E. (2014). Developing and playing chemistry games to learn about elements, compounds, and the periodic table: Elemental periodica, compundica, and groupica. Journal of Chemical Education, 91(4), 531-535. http://dx.doi.org/10.1021/ed4002249

Bilir, V. (2009). The effect of supporting organic chemistry lesson with experimental method on students' success in the secondary education. Master thesis, Education Sciences Institute, Gazi University, Ankara, Turkey.

Bradley, J.C., Lancashire, R.J., Lang, ASID, \& Williams, A.J. (2009). The spectral game: Leveraging open data and crowd sourcing for education. Journal of Cheminformatics, l(9), 1-10. http://dx.doi.org/10.1186/1758-2946-1-9

Brooks, A.M., \& Tollison, A.C. (2009). Making verbal pauses taboo®: Gaming to improve communication. Communication \& Theater Association Minnesota Journal, 36, 134-138.

Brown, B. A. (2013). The language-identity dilemma: An examination of language, cognition, identity, and their associated implications for learning. In J. A. Bianchini, V. L. Akerson, A. C. Barton, O. Lee, \& A. Rodriguez (Eds.), Moving the equity agenda forward: Equity research, practice, and policy in science education (pp. 223-239). Cultural Studies of Science Education 5, Springer.

Büyüköztürk, Ş. (2007). Experimental design pretest-posttest control group design and data analysis. Ankara: PegemA Publishing.

Campbell, S., \& Muzyka, J. (2002). Chemistry game shows. Journal of Chemical Education, 79(4), 458. http://dx.doi.org/10.1021/ed079p458

Capps, K. (2008). Chemistry taboo: An active learning game for the general chemistry classroom. Journal of Chemical Education, 85(4), 518. http://dx.doi.org/10.1021/ed085p518

Christensen, L. B. (2004). Experimental methodology. Boston, MA: Pearson Allyn and Bacon.

Cohen, J. (1988). Statistical power analysis for the behavioral sciences. Hillsdale, NJ: Erlbaum.

Cohen, J. (1992). A power primer. Psychological Bulletin, 112(1), 155-159. http://dx.doi.org/10.1037/0033-2909.112. 1.155

Cohen, L., Manion, L., \& Morrison, K. (2005). Research methods in education (5th Ed.). London, NewYork: Routledge Falmer.

Costa, M. J. (2007). Carbohydeck: A card game to teach the stereochemistry of carbohydrates. Journal of Chemical Education, 84(6), 977-978. http://dx.doi.org/10.1021/ed084p977

Crute, T. D. (2010). Effective use of games and puzzles in the chemistry classroom. In S. Basu-Dutt (Ed.), Making chemistry relevant: Strategies for including all students in a learner-sensitive classroom environment (pp. 284-297). NJ, USA: John Wiley \& Sons, Inc.

Crute, T. D. (2000). Classroom nomenclature games-BINGO. Journal of Chemical Education, 77(4), 481-482. http://dx.doi.org/10.1021/ed077p481

Deavor, J. P. (2001). Who wants to be a (chemical) millionaire?. Journal of Chemical Education, 78(4), 467. http://dx.doi.org/10.1021/ed078p467

DeVos, W., Van Berkel, B., \& Verdonk, A. (1994). A coherent structure of the chemistry curriculum. Journal of Chemical Education, 71(9), 743-746. http://dx.doi.org/10.1021/ed071p743

Duffy, A. M. (2006). Students' ways of understanding aromaticity and electrophilic aromatic substitution reactions. Doctoral dissertation, Mathematics and Science Education, University of California, San Diego, USA.

Eastwood, M. L. (2013). Fastest fingers: A molecule-building game for teaching organic chemistry. Journal of Chemical Education, 90(8). http://dx.doi.org/10.1021/ed3004462

Ellis, J. W. (1994). How are we going to teach organic chemistry if the task force has its way? Journal of Chemical 
Education, 71(5), 399-403. http://dx.doi.org/10.1021/ed071p399

Ellis, P. D. (2010). The essential guide to effect sizes: Statistical power, meta-analysis, and the interpretation of research results. Cambridge: Cambridge University Press. http://dx.doi.org/10.1017/CBO9780511761676

Erdik, E. (2005). Using building-block puzzles to practice drawing organic mechanisms. Journal of Chemical Education, 82(9), 1325-1326. http://dx.doi.org/10.1021/ed082p1325

Fang, Z. (2005). Scientific literacy: A systemic functional linguistics perspective. Science Education, 89, 335-347. http://dx.doi.org/10.1002/sce.20050

Fleiss, J. L., Levin, B., \& Paik, M. C. (2003). Statistical methods for rates and proportions (3rd ed.). New York: John Wiley \& Sons. http://dx.doi.org/10.1002/0471445428

Franco-Mariscal, A. J., Oliva-Martinez, J. M, \& Bernal-Marquez, S. (2012). An educational card game for learning families of chemical elements. Journal of Chemical Education, 89(8), 1044-1046. http://dx.doi.org/10.1021/ed200542x

Gabel, D. L., Samuel, K. V., \& Hunn, D. (1987). Understanding the particulate nature of matter. Journal of Chemical Education, 64(8), 695-697. http://dx.doi.org/10.1021/ed064p695

Garris, R., Ahlers, R., \& Driskell, J. E. (2010). Games, motivation, and learning: A research and practice model. Simulation \& Gaming, 33 (4), 441-467. http://dx.doi.org/10.1177/1046878102238607

Gee, J. (2005). Language in the science classroom: Academic social languages as the heart of school-based literacy. In R. Yerrick \& W.-M. Roth (Eds.), Establishing scientific classroom discourse communities: Multiple voices of teaching and learning research (pp. 19-37). Mahwah, NJ: Lawrence Erlbaum Associates.

Genç, M., Genç, T., \& Yüzüak, A. V. (2012). Determination of misconceptions by games: Taboo game. Mustafa Kemal University Journal of Social Sciences Institute, 9(20), 581-591.

Gmitrova, V., Podhajecká, M., \& Gmitrov, J. (2009). Children's play preferences: Implications for the preschool education. Early child development and care, 179(3), 339-351. http://dx.doi.org/10.1080/03004430601101883

Greengold, S. (2005). The match game: A discovery of the laboratory equipment used in general chemistry. Journal of Chemical Education, 82(4), 547-548. http://dx.doi.org/10.1021/ed082p547

Gublo, K. I. (2003). A laboratory safety trivia game. Journal of Chemical Education, 80(4), 425. http://dx.doi.org/10.1021/ed080p425

Güney, N., \& Aytan, T. (2014). A proposal of activity to improve active vocabulary: Taboo. Asos Journal, 2 (5), 617-628. http://dx.doi.org/10.16992/ASOS.326

Hanson, R. M. (2002). The chemical name game. Journal of Chemical Education, 79(11), 1380. http://dx.doi.org/10.1021/ed079p1380.1

Harmon, A., \& Crutcher, C. (2008). Math isn't taboo: Using a popular board game to reinforce math vocabulary in a 4th grade classroom. Research Innovation, 81-93. Retrieved from http://fortbend.k12.tx.us/accountability/ actionResearch/default.cfm, accessed 23 July 2015.

Johnson, R. B., \& Christensen, L. B. (2000). Educational research: Quantitative and qualitative approaches. Boston: Allyn and Bacon.

Jensen, W. B. (1998). Logic, history, and the chemistry textbook: Does chemistry have a logical structure? Journal of Chemical Education, 75(6), 679-687. http://dx.doi.org/10.1021/ed075p679

Hassan, A. K., Hill, R. A., \& Reid, N. (2004). Ideas underpinning success in an introductory course in organic chemistry. University Chemistry Education, 8(2), 40-51.

Karasar, N. (2005). Scientific research method(15th ed.). Ankara: Nobel Publishing.

Kavak, N. (2012). ChemOkey: A game to reinforce nomenclature. Journal of Chemical Education, 89(8), 1047-1049. http://dx.doi.org/10.1021/ed3000556

Kind, V. (2004). Beyond appearances: Students' misconceptions about basic chemical ideas (2nd ed.). London: Royal Society of Chemistry.

Knudtson, C. A. (2015). ChemKarta: A card game for teaching functional groups in undergraduate organic chemistry, Journal of Chemical Education, 92(9), 1514-1517. http://dx.doi.org/10.1021/ed500729v 
Koether, M. C. (2003). The name game: Learning the connectivity between the concepts. Journal of Chemical Education, 80(4), 421-422. http://dx.doi.org/10.1021/ed080p42

Lemke, J. L. (1990). Talking science: Language, learning, and values. Norwood, NJ: Ablex.

Marczyk, G., DeMatteo, D., \& Festinger, D. (2005). Essentials of research design and methodology. Canada: John Wiley \& Sons.

Martin, M. (1985). Concepts of science education: A philosophical analysis (2nd Ed.). USA: University Press of America.

Martorella, P. H. (1986). Teaching concepts (3rd ed.). In J. M. Cooper (Ed.), Classroom teaching skill (pp.182-223). Lexington, Mass: D.C. Health \& Co.

Maxwell, S. \& Delaney, H. (1990). Designing experiments and analyzing data. Pacific Grove, CA: Brooks/Cole.

Merwin, M. M. (2003). Forbidden words: A strategy for studying psychology. Teaching of Psychology, 30(3), 242-244.

Meyer, P.G. (2005). A study of how precursor key concepts for organic chemistry success are understood by general chemistry students. Doctoral dissertation, Western Michigan University, Kalamazoo,Michigan, USA.

Michalek, B. J., \& Hanson, R. M. (2006). Give them money: the Boltzmann game, a classroom or laboratory activity modeling entropy changes and the distribution of energy in chemical systems. Journal of Chemical Education, 83(4), 581-588. http://dx.doi.org/10.1021/ed083p581

Morris, T. A. (2011). Go chemistry: A card game to help students learn chemical formulas. Journal of Chemical Education, 88 (10), 1397-1399. http://dx.doi.org/10.1021/ed100661c

Myers, S. A. (2003). The molecular model game. Journal of Chemical Education, 80(4), 423-424. http://dx.doi.org/10.1021/ed080p423

Nakhleh, M. B. (1992). Why some students don't learn chemistry. Journal of Chemical Education, 69 (3), 191-196. http://dx.doi.org/10.1021/ed069p191

Olbris, D. J., \& Herzfeld, J. (2002). Depletion: A game with natural rules for teaching reaction rate theory. Journal of Chemical Education, 79(10), 1232-1234. http://dx.doi.org/10.1021/ed079p1232

Olimpo, J. T., Davis, S., Lagman, S., Parekh, R., \& Shields, P. (2010). Learning can be all fun and games: Constructing and utilizing a biology taboo wiktionary to enhance student learning in an introductory biology course. Journal of Microbiology \& Biology Education, 11(2), 164-165. http://dx.doi.org/10.1128/jmbe.v11i2.191

Randel, J. M., \& Morris, B. A. (1992). The effectiveness of games for educational purposes: A review of recent research. Simulation and Gaming, 23 (3), 261-277. http://dx.doi.org/10.1177/1046878192233001

Rieber, L. P., Smith, L., \& Noah, D. (1998). The value of serious play. Educational Technology, 38(6), 29-37.

Russell, J. V. (1999). Using games to teach chemistry: An annotated bibliography. Journal of Chemical Education, 76(4), 481-484. http://dx.doi.org/10.1021/ed076p481

Russell, J. W., Kozma, R. B., Jones, T., Wykoff, J., Marx, N., \& Davis, J. (1997). Use of simultaneous-synchronized macroscopic, microscopic, and symbolic representations to enhance the teaching and learning of chemical concepts. Journal of Chemical Education, 74(3), 330-334. http://dx.doi.org/10.1021/ed074p330

Samide, M. J., \& Wilson, A. M. (2014). Games, games, games; playing to engage with chemistry concepts. The Chemical Educator, 19, 167-170.

Sanger, M. J., Phelps, A. J., \& Fienhold, J. (2000). Using a computer animation to improve students' conceptual understanding of a can-crushing demonstration. Journal of Chemical Education, 77(11), 1517-1520. http://dx.doi.org/10.1021/ed077p1517

Sarma, N. S. (2006). Chemistry concepts and vocabulary from root words. Resonance, 11(7), 80-98. http://dx.doi.org/10.1007/BF02835997

Schreck, J. O. (1992). Enhancing interest in organic chemistry. Part II. Organic chemistry squares: A game for reviewing organic chemistry. Journal of Chemical Education, 69(3), 233-234. http://dx.doi.org/10.1021/ed069p233.2

Stringfield, T. W., \& Kramer, E. F. (2014). Benefits of a game-based review module in chemistry courses for 
nonmajors. Journal of Chemical Education, 91 (1), 56-58. http://dx.doi.org/10.1021/ed300678f

Suits, J. P. (2000, April). Conceptual change and chemistry achievement: A two dimensional model. Paper presented at the 81st Annual Meeting of the American Educational Research Association, New Orleans, LA.

Taşdelen, U., Köseoğlu, F., Özdem, Y., \& Demirdöğen, B. (2010, November). Interactive evaluation of nature of science: A taboo-like game as a final semester activity. Paper presented at ICERI 2010 International Conference of Education, Research and Innovation, Madrid, Spain.

Türk, Ö., Güngör, Ö., \& Karaaslan, G. (2011, July). Project report of Taboology group: Math-Taboo. Paper presented at the High School Teacher Project Consultancy Training Workshop: High school I, University of 18 Mart, Çanakkale, Turkey.

Vygotsky, L. (1986). Thought and language. Cambridge, MA: The MIT press.

Wasacz, J.T. (2010). Organic chemistry preconceptions and their correlation to student success. Doctoral Dissertation, University of Northern Colorado, USA.

Wellington, J., \& Osborne J. (2001). Language and literacy in science education. Philadelphia, PA: Open University Press.

Williams, K. R. (2008). May the best chemist win! Journal of Chemical Education, 85(10), 1314-1315. http://dx.doi.org/10.1021/ed085p1314

Ziv, A. (1988). Teaching and learning with humor: Experiment and replication. Journal of Experimental Education, 57(1), 4-15. http://dx.doi.org/10.1080/00220973.1988.10806492 